\section{Signet-ring cell cancer of the colon presenting as facial and gastroduodenal metastasis 7 years after sigmoidectomy}

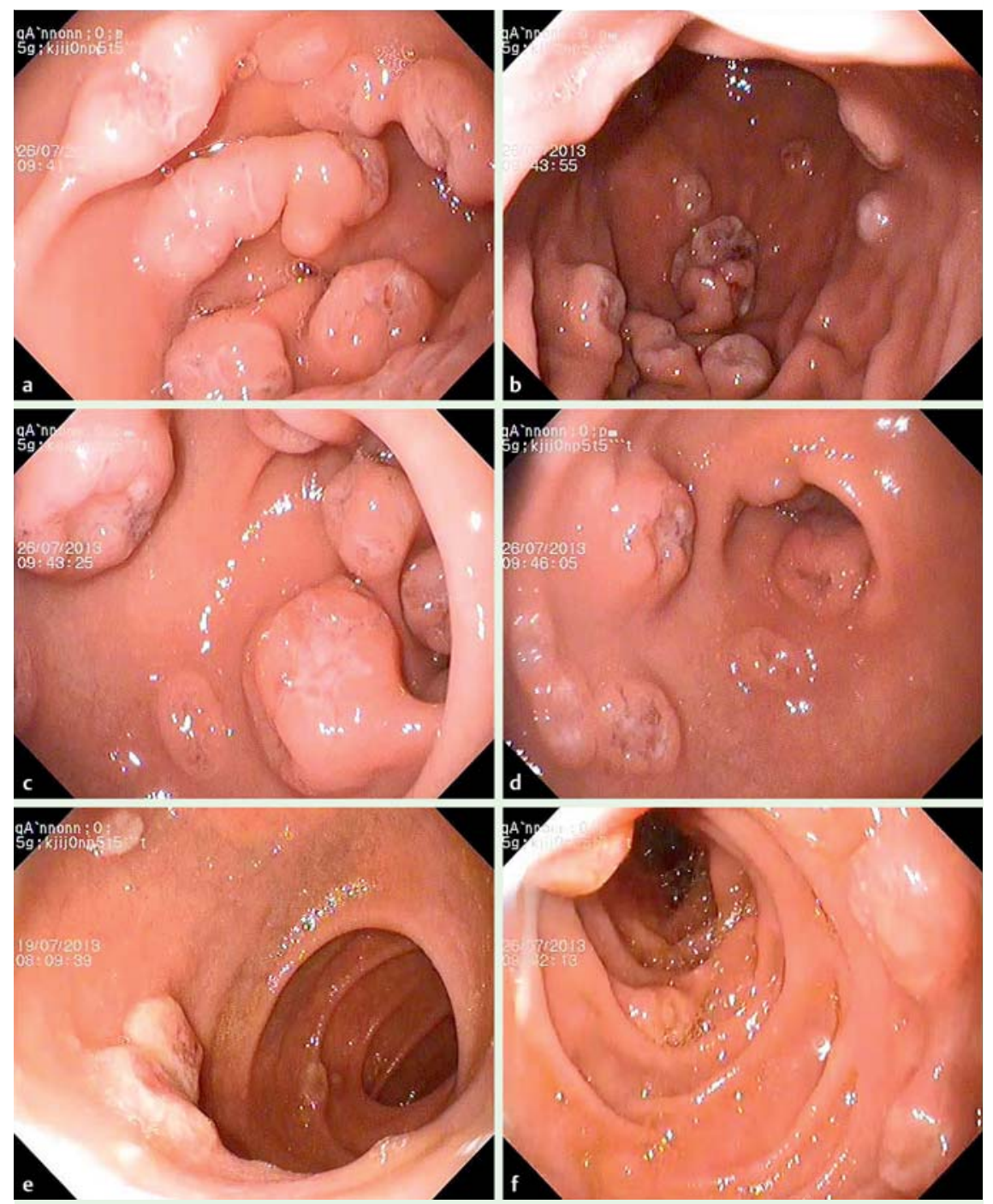

Fig. 1 Endoscopic images showing lesions with a smooth surface, normal color, and bridging folds, which resemble submucosal tumors with central depression or ulceration, covering all of the: a gastric fundus; b gastric body; c gastric antrum; $\mathbf{d}$ gastric angle; e duodenal bulb; $\mathbf{f}$ second portion of the duodenum.

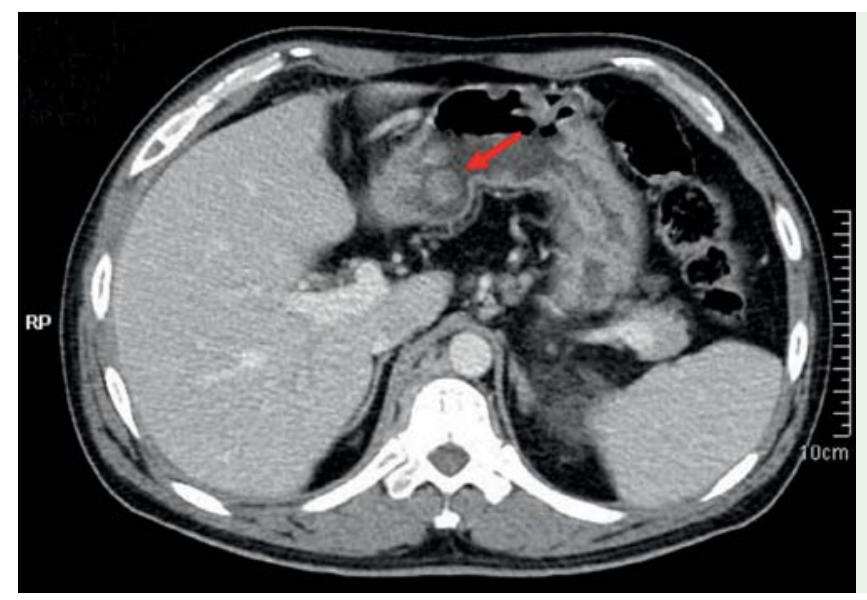

A 46-year-old man presented with a red, nonpainful, fast-growing nodule with ulceration in the face, along with nausea and weight loss. Seven years ago, he had undergone sigmoidectomy for signet-ring cell adenocarcinoma (stage T2NOMO) in the sigmoid colon, and he had been followed up and appropriately screened regularly for cancer recurrence after the surgical intervention.

Colonoscopy showed normal mucosa and no local recurrence. Because the patient complained of nausea and weight loss, gastroscopy was performed to exclude a primary gastric tumor. This revealed multiple nodules covering the whole of the gastric fundus, gastric body, gastric antrum, and gastric angle. Multiple nodules were also found within the bulb and second portion of the duodenum ( Fig. 1 ). On endoscopic examination, the lesions had a smooth surface, normal color, and bridging folds, which resembled submucosal tumors with central depression or ulceration, corresponding to the "bull'seye sign" on radiographs ( $\bullet$ Fig. 2 ). Destroyed gastric mucosal and submucosal anatomy were also shown by endoscopic ultrasonography ( $\bullet$ Fig.3).

Histopathological examination of nodular lesions from the skin ( Fig.4) and gastrointestinal lesions revealed diffuse infiltration of the cutaneous/mucosal and subcutaneous/submucosal tissue by signet-ring tumor cells ( $\bullet$ Fig.5). Immunohistochemical analyses indicated diagnoses of secondary tumors, all suggestive of colonic origin. The patient was without hepatic or pulmonary involvement until his death, 7 months later.

Facial metastases of colorectal cancer are extremely uncommon, with few descriptions in the literature [1]. The face may be the first site of recurrence of an underlying cancer, but this usually occurs within $4-5$ years of the primary resection $[2,3]$. Synchronous gastric and duodenal metastatic tumors from the colon are very rare. More frequently, lesions are located in the middle or upper third of the stomach $[4,5]$. Endoscopically, most resemble submucosal tumors with a central depression [4]. The liver and lung are the usual locations of distant metastases from colorectal cancer. The patient we report presented with remote facial cutaneous and extensive gastrointestinal mucosal metastases, not associated with other visceral secondary tumors up until the patient's death. This case thus shows unusual features, both clinical and pathogenetic, that have not been previously described. 


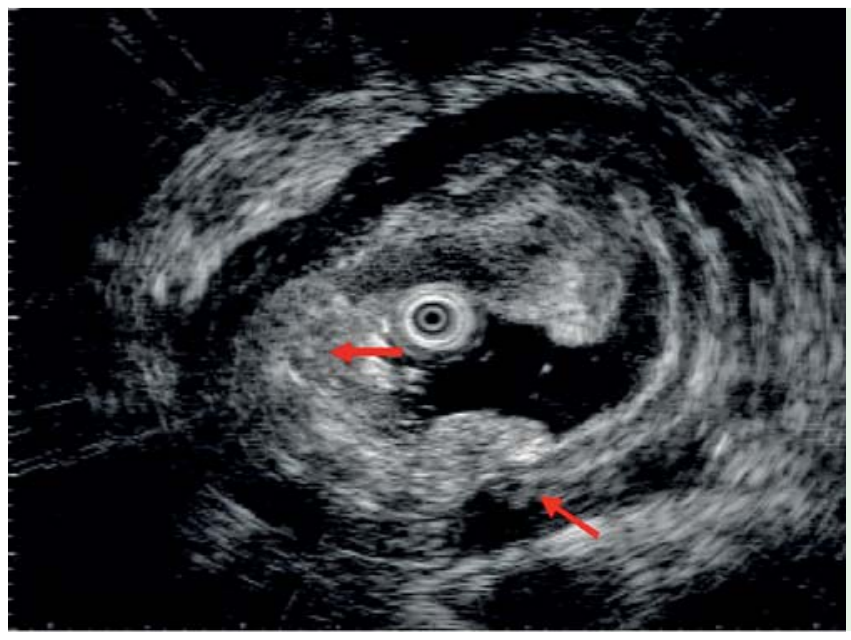

Fig. 3 Endoscopic ultrasound image showing destroyed mucosal and submucosal anatomy in the gastric antrum (arrows).

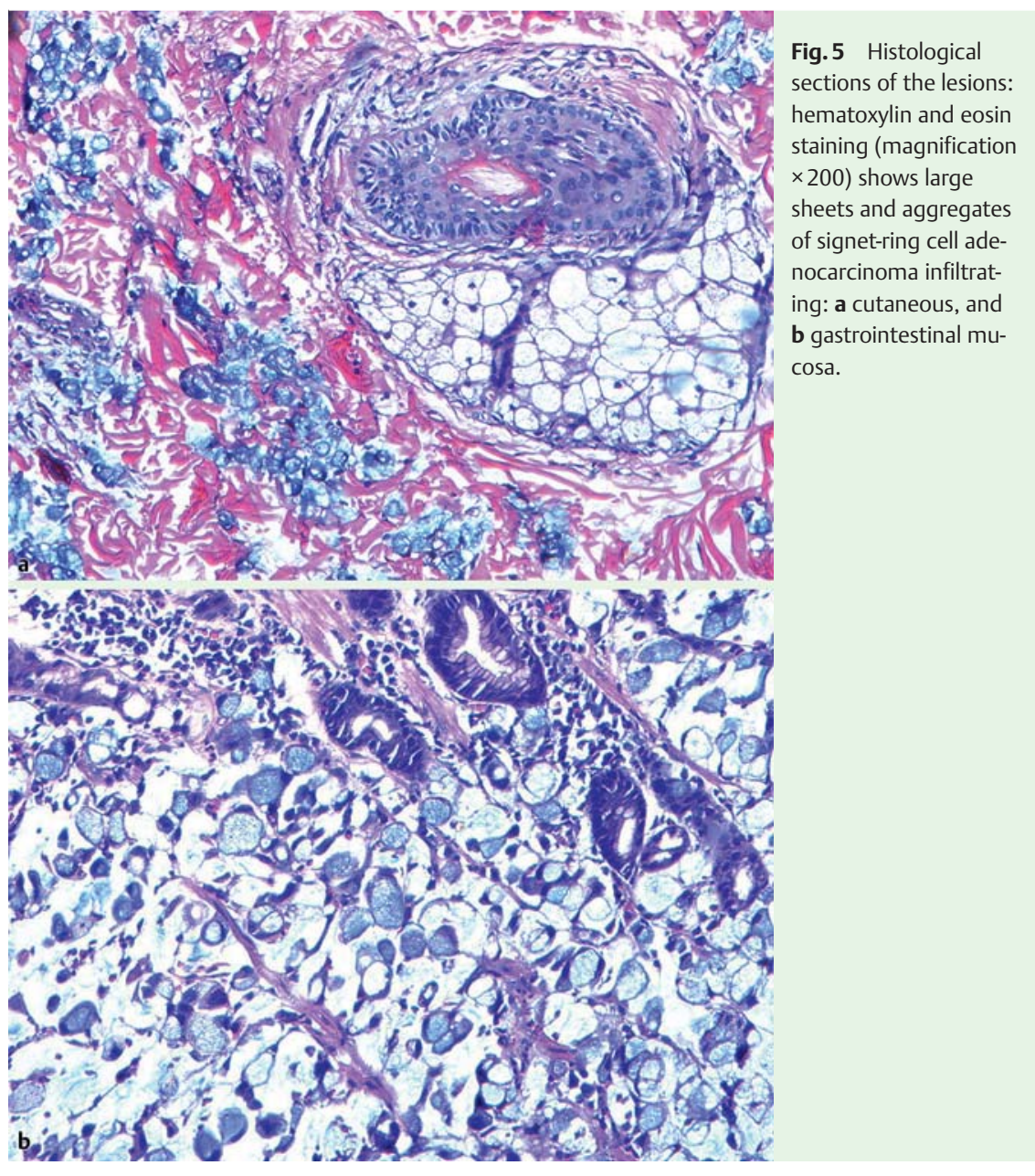

Endoscopy_UCTN_Code_CCL_1AB_2AD_3AB

Bin Li ${ }^{1}$, Qian Lí ${ }^{2}$, Xiang Li ${ }^{3}$, Guiying Zhang ${ }^{2}$, Liangfang Shen ${ }^{1}$

Competing interests: None
${ }^{1}$ Division of Oncology, Xiangya Hospital, Central South University, Changsha, 410008, PR China

2 Division of Gastroenterology, Xiangya Hospital, Central South University, Changsha, 410008, PR China Division of Pathology, Xiangya Hospital, Central South University, Changsha, 410008, PR China

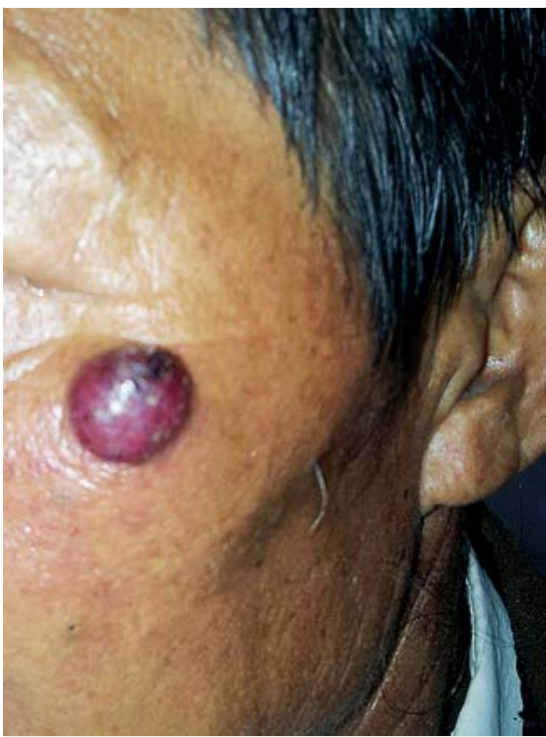

Fig.4 Red nonpainful nodule with ulceration on the left side of the face.

\section{Acknowledgments \\ $\nabla$}

This work was supported by grants from the National Natural Scientific Foundation of China (no.81200366) and The Key Subject Education Department of Hunan ([2012] 594).

\section{References}

1 Relles D, Fong Z, Burkhart $R$ et al. Facial cutaneous metastasis of colon adenocarcinoma. Am Surg 2012; 78: E454-456

2 Shahidi-Dadras M, Rahimi H. Facial metastasis from colon cancer. Arch Iran Med 2011; 14: $64-65$

3 Hashimi Y, Dholakia S. Facial cutaneous metastasis of colorectal adenocarcinoma. BM] Case Rep 2013, bcr-2013-009875

4 Oda KH, Yamao T, Saito D et al. Metastatic tumors to the stomach: analysis of 54 patients diagnosed at endoscopy and 347 autopsy cases. Endoscopy 2001; 33: 507-510

5 Hsu CC, Chen JJ, Changchien CS. Endoscopic features of metastatic tumors in the upper gastrointestinal tract. Endoscopy 1996; 28 : $249-253$

Bibliography

DOI http://dx.doi.org/

10.1055/s-0034-1365151

Endoscopy 2014; 46: E220-E221

(c) Georg Thieme Verlag KG

Stuttgart · New York

ISSN 0013-726X

Corresponding author

Liangfang Shen, MD, PhD

Xiangya Road 87th

Changsha 410008

Hunan

PR China

ShLFCSUXY@163.com 